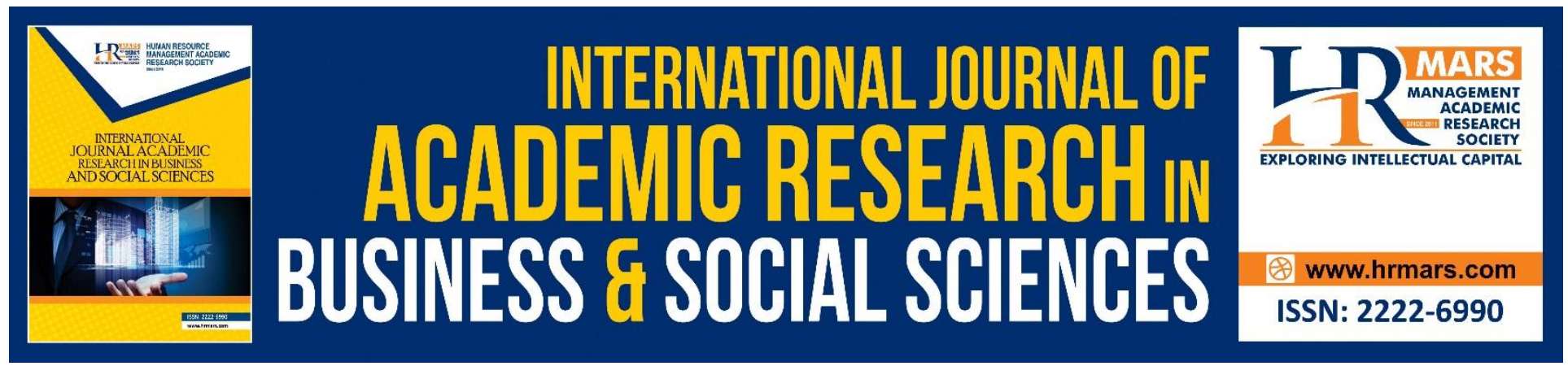

\title{
Measuring Factors Affecting the Autonomy of Nurses Work
}

\author{
Sami Abuseif \\ Omar Ayaad \\ Eyad Abu Al-Haijaa
}

To Link this Article: http://dx.doi.org/10.6007/IJARBSS/v8-i12/5323

DOI: $10.6007 /$ IJARBSS/v8-i12/5323

Received: 13 Nov 2018, Revised: 17 Dec 2018, Accepted: 27 Dec 2018

Published Online: 02 Jan 2019

In-Text Citation: (Abuseif, Ayaad, \& Al-Haijaa, 2018)

To Cite this Article: Abuseif, S., Ayaad, O., \& Al-Haijaa, E. A. (2018). Measuring Factors Affecting the Autonomy of Nurses Work. International Journal of Academic Research in Business and Social Sciences, 8(12), 1785-1796.

\section{Copyright: (c) 2018 The Author(s)}

Published by Human Resource Management Academic Research Society (www.hrmars.com)

This article is published under the Creative Commons Attribution (CC BY 4.0) license. Anyone may reproduce, distribute, translate and create derivative works of this article (for both commercial and non-commercial purposes), subject to full attribution to the original publication and authors. The full terms of this license may be seen

at: http://creativecommons.org/licences/by/4.0/legalcode

\section{Vol. 8, No. 12, 2018, Pg. 1785 - 1796}

Full Terms \& Conditions of access and use can be found at http://hrmars.com/index.php/pages/detail/publication-ethics 


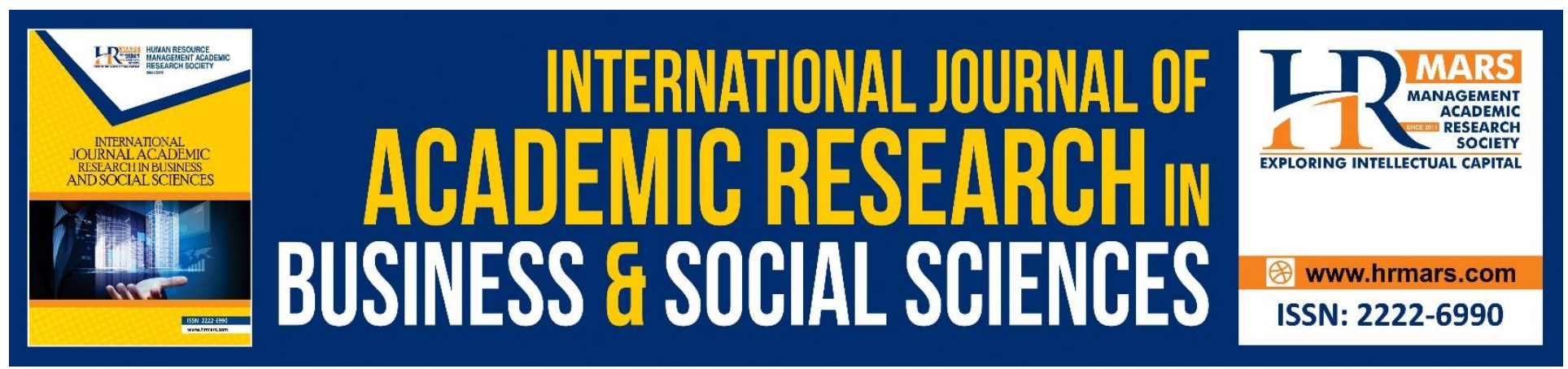

\title{
Measuring Factors Affecting the Autonomy of Nurses Work
}

\author{
Sami Abuseif \\ Al-Ghad International College for Applied Medical Sciences, Najran, KSA \\ Email: samibsf@yahoo.com \\ Omar Ayaad \\ King Hussain Cancer Center, Amman, Jordan \\ Email: omarayyad86@yahoo.com \\ Eyad Abu Al-Haijaa \\ Alabdali Hospital, Amman, Jordan \\ Email: Oa.08084@khcc.jo
}

\begin{abstract}
Research Aim: The research aimed to examine the factors that affecting the autonomy of nurses' work.

Method: A cross sectional descriptive design was conducted in two of public hospitalsin KSA using a developed questionnaire. Randomsampling technique was utilized to choose 400 nurses in the participated hospitals. The collected data was analyzed using SPSS software version 21.

Results: The findings showed there wasa significant correlation between nurses' perception of autonomy of their work and organization culture and climate; relation and cooperation; training and development; compensation and rewards; and adequacy of resources and facilities.

Conclusion: Many factor affecting the nurses' perception of their work including organization culture, relation and cooperation, compensation and rewards, training and development, and adequacy of resources.
\end{abstract}

Keywords: Autonomy

\section{Introduction}

Nowadays, the science of nursing is more sophisticated; and the profession of nursing is more evident in the healthcare settings. Nurses are performingmore complex roles and multiple responsibilities (Mrayyan, 2004), thus, presenting of autonomy isa critical feature ofthe nursing profession(Maharmeh, Alasad, Salami, Saleh, \& Darawad, 2016). Autonomy is defined as thework 
environment power that enables the employees doing their maximum efforts (Maylone, Ranieri, Griffin, Mcnulty, \& Fitzpatrick, 2011). The autonomy in nursing can be practiced for both the nursing profession and the individual nurses. Professional autonomy represents the nurses' abilities to independently formulate and develop their guidelines and standards. Individual autonomy describes the ability of nurses to practice their professional standards and guidelines (Abuseif \& Ayaad, 2018; MacDonald, 2002).

Autonomy is considered as an essential element of professional development for nurses (Varjus, Leino-Kilpi, \& Suominen, 2011). For this reason, improving the autonomy of nurses work promotes theirknowledge and experiences (Parahoo, 2000). Moreover, the autonomy of nurses' practices has a significant positive impact on patients, nurses, and hospitals in terms of improving the nurses'satisfaction, motivation, and decreases their turnover which enhances the patient perception of quality of nursing care and satisfaction. Indeed, the improvement in care has a positive influence on patient outcome (Abuseif \& Ayaad, 2018; Maylone et al., 2011).

Autonomy can be affected by many factors such as organizational culture and climate (Elliott, 2003), the relationship and cooperation (Gammelgaard, McDonald, Tüselmann, Dörrenbächer, \& Stephan, 2011), facilities and adequate resources,compensation and rewards, and training and development (Gordon, 2017). The autonomy is recognized by front managers as the highest priority due to the increasing involvements of nurses in multi-disciplinary discussions and enhancing the nurses' patient care roles and responsibilities (Maharmeh et al., 2016).

For this reason, autonomy is recognized as an essential part of magnet recognition program in exemplary practices standards. It is measured by the level of support and the promotion methods in the organization. Autonomy is classified as clinical and organizational (Clark, 2006; Kramer \& Schmalenberg, 2003; Westendorf, 2007).

Theoretically, the subject of autonomy has been extensively studied in the Western countries but its study is somewhat neglected in the region of the Middle East. Thus, the current study adds to the literature on autonomy in the context of the Middle East, particularly in KSA, as well as it provides an explanation of the autonomy among nurses.

To my knowledge, there is no study in KSA examining the relationship between nurses' perception of organization culture and climate, relationship and cooperation, facilities and adequate resources, compensation and rewards, training and development, and the nurse perception of autonomy of their work. Subsequently, the purpose of this study was to examine how much these factors are affecting the nurses' perception of work autonomy.

\section{Literature Review}

Autonomy of nurse work has been a subjectof interest for decades (Varjus et al., 2011). It was defined by many researches as the power to make choices (Gammelgaard et al., 2011; MacDonald, 2002; Maharmeh et al., 2016; Maylone et al., 2011; Rafferty, Ball, \& Aiken, 2001; Varjus et al., 2011). Several studies in the literature discussed many factors that may affect the perception of autonomy among workers (Gagnon, Bakker, Montgomery, \& Palkovits, 2010; Rafferty et al., 2001; Sigler \& Pearson, 2000). In 2000, A study conducted in four textile plants to examine the relationship between organizational culture and staff autonomy and empowerment showed that there wasa significant positive relationship between perceived organizational cultures in terms of structure, vision, mission, 
strategic goals, shared governance model, systems, and workers perception of autonomy and empowerment (Sigler \& Pearson, 2000).

A postal questionnaire study was conducted in 32 hospitals in England in which 10022 nurses have participated to investigate the correlation between staff cooperation and relationship and nurse autonomy found that nurses with high perception of teamwork and cooperation felt more autonomous and involved in their practice. Also there was an observed significant correlation between cooperation and relationship and autonomy (Rafferty et al., 2001).

Furthermore, a study aimed to investigate oncology nurses' perceptions of autonomy and its implementation in practice utilizing Leininger'seth no nursing method, and semi-structured interviews with 15 oncology nurses showed that autonomy is promoted by professional development including availability of adequate training and education (Gagnon et al., 2010).Additionally, the availability of resources and facilities to share information and communication tools is considered an important keys for improving the workers perception of autonomy in their works (Calvo, Peters, Johnson, \& Rogers, 2014).

Critical care nurses' in KSA were found to be autonomous in decision-making and independent in their clinical practice (Maharmeh, 2017). Another study was conducted in KSA to review nurse managers actions to promote the autonomy of their nurses reported that the improvement of relations with other healthcare professionals and the enhancement of working life and culture were the main actions utilized by the nurse managers to improve the nurses perception of their autonomy (Mrayyan, 2004).

\section{Conceptual Model}

The study model was developed based on literature review. The five independent factors include five factors (organization culture and climate, the relationship and cooperation, facilities and adequate resources, compensation and rewards, and training and development). The dependent factor includes autonomy of work factor (Calvo et al., 2014; Conroy \& Douglas Coatsworth, 2007; MacDonald, 2002; M Maharmeh, 2017; Maylone et al., 2011; Mrayyan, 2004). 
INTERNATIONAL JOURNAL OF ACADEMIC RESEARCH IN BUSINESS AND SOCIAL SCIENCES

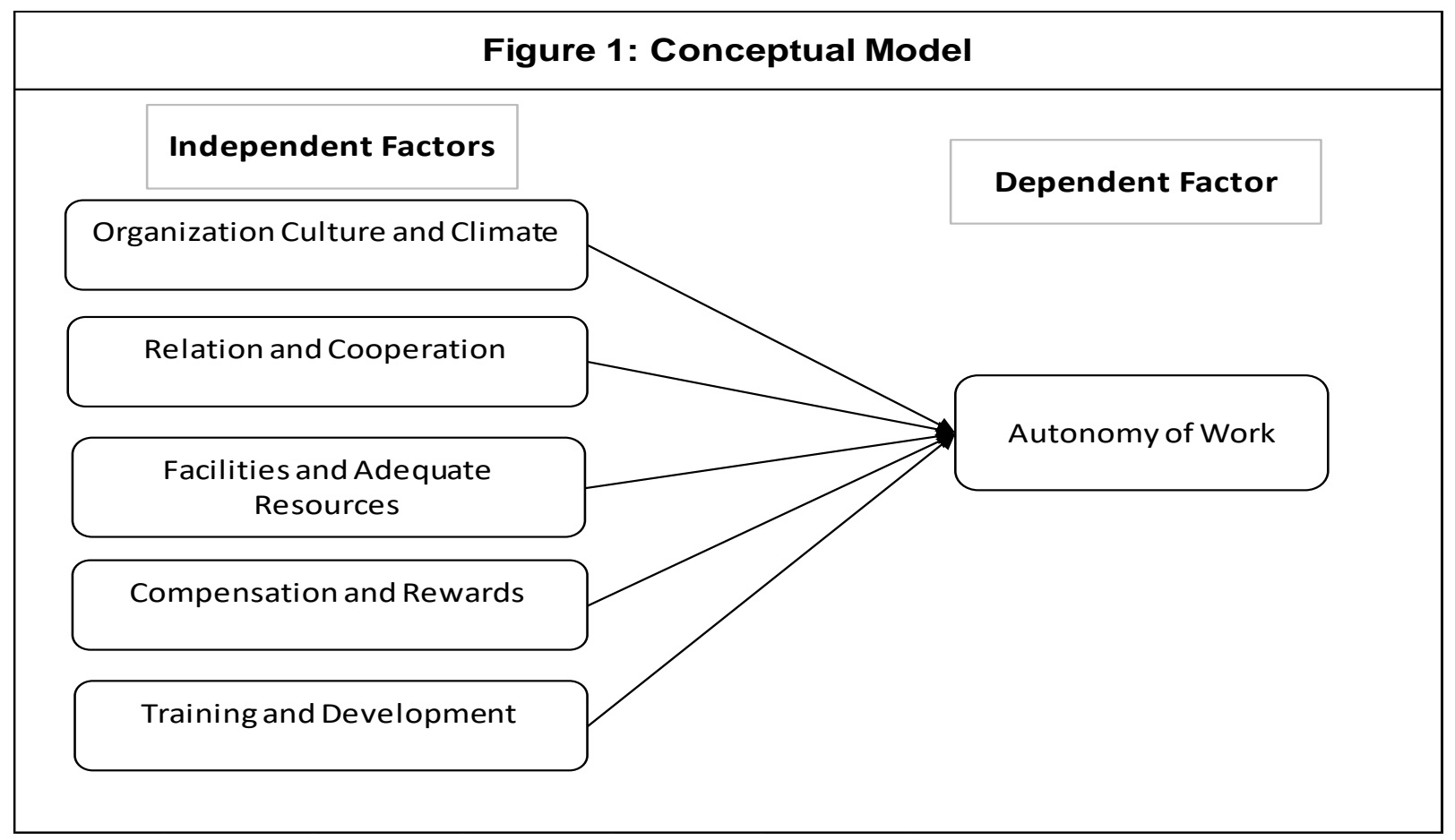

\section{Aim and Hypothesis}

This study aimed to examine how much the organization culture and climate factor, relationship and cooperation factor, facilities and adequate resources factor, compensation and rewards factor, and training and development factor are affecting the nurses' perceptions of their work autonomy. The hypotheses of the study will be intended to test the propositions concerning the relationships. The hypotheses of the study were as follows.

- Ha1: there is a significant positive relationship between the total nurses' perception of affecting factors, and autonomy.

- Ha2: there is a positive significant relationship betweenthe nurses' perception of organization culture and climate, and autonomy.

- Ha3: there is a significant relationship positive between the nurses' perception of cooperation and relations, and autonomy.

- Ha4: there is a significant positive relationship between the nurses' perception of training and development, and autonomy.

- Ha5: there is asignificant positive relationship between the nurses' perception of compensation and rewards, and autonomy.

- Ha6: there is asignificant positive relationship between the nurses' perception of adequate facilities and resources, and autonomy.

\section{Research Method}

Design: Across sectional descriptive design was used to identify and examine how much the factors affecting the perception the autonomy of nurses' work. 
Setting: The study was conducted in two large hospitals in KSA. The total bed capacity for both hospitals is around 400 beds with clinical nurses counted between 800-1000 nurses.

Population: All nurses in selected hospitals were eligible to participate in this study.

Sample: Random sampling technique was utilized to choose 400 nurses in the participated hospitals. Data collection: The study used a developed closed-ended structured questionnaire composing of 36 items. The questionnaire composed of six domains: organization culture and climate domain (seven questions), the relationship and cooperation domain (six questions), facilities and adequate resources domain (eight questions), compensation and rewards domain (five questions), training and development domain (four questions) and autonomy domain (six questions). The reliability coefficient of the questionnaire was 0.88 (Swamy \& Rashmi, 2015).

Data Analysis: The collected data was analyzed usingSPSS software version 21 includingdescriptive statistics including mean, standard deviations, frequency distributions, contingency tables and percentages were obtained for the different study variables as appropriate. The correlation between study variables was calculated using Pearson correlation coefficient ( $r$ ).

\section{Ethical Consideration}

The study was reviewed and approved by an Institutional Review Board and granted the researchers, the ethical approval to conduct data collection.

\section{Research Results}

Demographic data

During June 2018 until Sep 2018, 400 surveys were collected by nurses in the two hospitals. There was 210 female (53\%) and 190 male (47\%). The majority of participated nurses have a work experience between 1-5 years, holding a bachelor degree, and their age range between 20-29 years, and working in general wards. Only $10(2 \%)$ of them have a master degree. Table 1 presents the full demographic characteristics of the study sample. 
INTERNATIONAL JOURNAL OF ACADEMIC RESEARCH IN BUSINESS AND SOCIAL SCIENCES

Vol. 8, No. 12, Dec, 2018, E-ISSN: 2222-6990 @ 2018 HRMARS

Table 1: Demographic characteristics of Study Sample

\begin{tabular}{|c|c|c|}
\hline \multirow{2}{*}{$\begin{array}{l}\text { Demographic } \\
\text { characteristics }\end{array}$} & \multicolumn{2}{|c|}{ Total } \\
\hline & Number & $\%$ \\
\hline $\begin{aligned} & \text { Age } \\
&- 20-29 \\
& \bullet 31-39 \\
& \bullet 40-49 \\
& \text { Total } \\
&\end{aligned}$ & $\begin{array}{c}300 \\
90 \\
10 \\
400 \\
\end{array}$ & $\begin{array}{c}75 \% \\
23 \% \\
2 \%\end{array}$ \\
\hline $\begin{aligned} \text { Gender } & \\
& \text { - } \\
\bullet & \text { Male }\end{aligned}$ & $\begin{array}{l}210 \\
190 \\
\end{array}$ & $\begin{array}{l}54 \% \\
46 \% \\
\end{array}$ \\
\hline $\begin{array}{c}\text { Educational Level } \\
\text { - } \\
\text { - } \\
\text { - } \text { B.S.S.N } \\
\text { - M.S }\end{array}$ & $\begin{array}{c}25 \\
425 \\
10\end{array}$ & $\begin{array}{c}5 \% \\
90 \% \\
2 \%\end{array}$ \\
\hline $\begin{array}{l}\text { Work Experience in } \\
\text { the Hospital } \\
\begin{aligned} \text { - } & 1-5 \text { years } \\
\text { - } & 6-10 \text { years } \\
\text { - } & 11-15 \text { years } \\
\text { - } & >15 \text { years }\end{aligned}\end{array}$ & $\begin{array}{c}320 \\
63 \\
12 \\
6 \\
\end{array}$ & $\begin{array}{c}79 \% \\
18 \% \\
3 \% \\
1 \% \\
\end{array}$ \\
\hline $\begin{aligned} & \text { Units } \\
& \text { - ICUs } \\
& \text { - General Floor } \\
& \text { - Other }\end{aligned}$ & $\begin{array}{c}100 \\
290 \\
10 \\
\end{array}$ & $\begin{array}{c}19 \% \\
77 \% \\
4 \% \\
\end{array}$ \\
\hline
\end{tabular}

The findings showed that there was a significant correlation in the total mean of studied factors and the nurses' perception of autonomy in their work $(r=0.642, P<0.05)$. Furthermore, the findings showed that there was a significant correlation in each factor: organization culture and climate $(r=0.59, P<0.05)$; relation and cooperation $(r=0.50, P<0.05)$; training and development $(r=0.44$, $\mathrm{P}<0.05)$; compensation and rewards $(r=0.59, \mathrm{P}<0.05)$; and adequacy of resources and facilities $(r=0.56, P<0.05)$. The table 2 showed the results of nurse perception toward work life. 
INTERNATIONAL JOURNAL OF ACADEMIC RESEARCH IN BUSINESS AND SOCIAL SCIENCES

Vol. 8, No. 12, Dec, 2018, E-ISSN: 2222-6990 @ 2018 HRMARS

Table 2: The Results of Nurses' Perception

\begin{tabular}{|c|c|c|}
\hline & \multicolumn{2}{|c|}{$\begin{array}{l}\text { Autonomy of } \\
\text { Work }\end{array}$} \\
\hline & $\mathrm{R}$ & Sign. \\
\hline $\begin{array}{l}\text { - Organization Culture and } \\
\text { Climate }\end{array}$ & 0.59 & $<0.05^{*}$ \\
\hline - Relation and Cooperation & 0.50 & $<0.05^{*}$ \\
\hline - Training and Development & 0.44 & $<0.05 *$ \\
\hline - Compensation and Rewards & 0.59 & $<0.05^{*}$ \\
\hline $\begin{array}{l}\text { - Facilities and Adequacy of } \\
\text { Resources }\end{array}$ & 0.56 & $<0.05^{*}$ \\
\hline Total Factors & 0.642 & $<0.05^{*}$ \\
\hline
\end{tabular}

- Significant at $P$ value $<0.05$

According to the mentioned results, the all developed hypotheses are accepted at $p<0.05$ level, which is mean a significant correlation between the factors and the nursing perception of autonomy of their work as shown in the table (3).

Table 3: The Results of Research Hypothesis

\begin{tabular}{|l|l|}
\hline \multicolumn{1}{|c|}{ Hypotheses } & Result * \\
\hline $\begin{array}{l}\text { Ha1: there is a significant relationship between the total nurses' perception of } \\
\text { affected factors and autonomy. }\end{array}$ & Accepted \\
\hline$\circ \begin{array}{l}\text { Ha2: there is a significant relationship between the nurses' perception of } \\
\text { organization culture and climate and autonomy. }\end{array}$ & Accepted \\
\hline$\circ$ & Ha3: there is a significant relationship between the nurses' perception of \\
cooperation and relations and autonomy. & Accepted \\
\hline$\circ$ & Ha4: there is a significant relationship between the nurses' perception of training \\
and development and autonomy. & Accepted \\
\hline & Ha5: there is a significant relationship between the nurses' perception of \\
compensation and rewards and autonomy. & Accepted \\
\hline$\circ$ & Ha6: there is a significant relationship between the nurses' perception of adequate \\
facilities and resources and autonomy. & Accepted \\
\hline
\end{tabular}

- Significant at $P$ value $<0.05$

$\bullet$

Moreover, as the table (4) showed, the nurses related factors such as age, gender, educational level, work experience in the hospital, and working units have not had any impact on their perception of autonomy in work. 
INTERNATIONAL JOURNAL OF ACADEMIC RESEARCH IN BUSINESS AND SOCIAL SCIENCES

Vol. 8, No. 12, Dec, 2018, E-ISSN: 2222-6990 @ 2018 HRMARS

Table 4: Demographic data and Nurse Perception of Autonomy

\begin{tabular}{|c|c|c|}
\hline \multirow{2}{*}{ Demographic Data } & \multicolumn{2}{|c|}{ Total } \\
\hline & F test & Sig. \\
\hline - Age & 3.21 & 0.09 \\
\hline - Educational Level & 0.72 & 0.48 \\
\hline $\begin{array}{l}\text { - Work Experience in the } \\
\text { Hospital }\end{array}$ & 0.51 & 0.68 \\
\hline - Working Units & 1.04 & 0.37 \\
\hline
\end{tabular}

\section{Discussion}

This study intended to examine how much the factors affecting the nurse perception ofautonomy of nurses' work. The results indicate that there were many factors that can have an impact onnurses' perception of autonomy of their work. This study findingsare consistent with many studies discussing the impact of such factors (Fisher, Jabara, Poudrier, Williams, \& Wallen, 2016; Gammelgaard et al., 2011; Jingnan, 2011; Maylone et al., 2011; Rafferty et al., 2001; Sigler \& Pearson, 2000; Turner, Keyzer, \& Rudge, 2007; Varjus et al., 2011).

The organization culture and climate enable the nurses to work in cooperative behavior and manner according to values, norms, determined policies and procedures, motivation and reward system, view of leadership, hierarchy, authority relationships, working ethic, working hours, and operating environments. This behavior empowers nurses to advocate their practice and accordingly leads to enhance the perceptions of autonomy (Calvo et al., 2014; Mrayyan, 2004; Prichard \& Moore, 2016; Sigler \& Pearson, 2000).

Moreover, the availability of effective communication and relations between nurses, and between nurses and other healthcare providers empower the nurses to work as a team and to express their concern and feeling regarding the work environment and improvement opportunities and to share the knowledge regarding their practice which leads to enhance feeling of autonomy (Gammelgaard et al., 2011; Rafferty et al., 2001)

The significant positive relationship between the nurses' perceptions of their work autonomy and training and development level enables nurses to know and apply their evidence-based practices (Gagnon et al., 2010). According to many studies, the proper implementation of nursing's evidencebased practice has positively impacted the nurse professional development and nurse outcome which leads to increase the salary and bonuses. The proper implementation of nursing's evidencebased practice requires high perception of autonomy level. For this reason, the rewards and compensation is also significantly correlated with the perception of autonomy (Houlfort, Koestner, Joussemet, Nantel-Vivier, \& Lekes, 2002; Mccrae, 2012; Shaker \& Werner Woida, 2007; Turner et al., 2007).

Additionally, the availability of effective communication channels, e-collaborative tools such as email and interactive calls, transportation, and other resources have a significant impact in improving the cooperation and elation between nurses and other healthcare professionals, and improve the accessibility of nurses to evidence-based practice knowledge and sharing their experiences with other teams inside or outside the health organization. All these factors will enhance 
INTERNATIONAL JOURNAL OF ACADEMIC RESEARCH IN BUSINESS AND SOCIAL SCIENCES

Vol. 8, No. 12, Dec, 2018, E-ISSN: 2222-6990 @ 2018 HRMARS

their professional practice and improve their autonomy in their works (Conroy \& Douglas Coatsworth, 2007; Jingnan, 2011; Rafferty et al., 2001).

\section{Conclusion}

The autonomy of nurse works has been affected by several factors including organizational culture and climate factor, the relationship and cooperation, facilities and adequate resources, compensation and rewards, and training and development factors.

It is recommended to health and nurse managers to ensure adequate culture and climate, enhance the feeling of autonomy among staff including nurses, manage communication and relation, and enhance training and development in way that support and empower the nurses in the organization.

In theory, the autonomy is a subject has been neglected in the region of the Middle East. Furthermore, studies devoted to the examination of autonomy among nurses have been somewhat neglected in KSA prior to the present study, which makes a significant contribution theoretically.

\section{References}

Abuseif, S., \& Ayaad, O. (2018). The Relationship between Organizational Commitment and Nurses' Turnover Intention Behavior at Tertiary Private Hospitals in Najran, KSA. International Journal of Academic Research in Business and Social Sciences (6),8,(764-772.

Calvo, R. a., Peters, D., Johnson, D., \& Rogers, Y. (2014). Autonomy in technology design. Proceedings of the Extended Abstracts of the 32nd Annual ACM Conference on Human Factors in Computing Systems - CHI EA '14, 37-40. https://doi.org/10.1145/2559206.2560468

Clark, M. L. (2006). The Magnet Recognition Program and Evidence-Based Practice. Journal of Perianesthesia Nursing, 21(3), 186-189. https://doi.org/10.1016/j.jopan.2006.03.008

Conroy, D. E., \& Douglas Coatsworth, J. (2007). Assessing autonomy-supportive coaching strategies in youth sport. Psychology of Sport and Exercise, 8(5), 671-684. https://doi.org/10.1016/j.psychsport.2006.12.001

Elliott, A. (2003). Subjectivity, Culture, Autonomy: Castoriadis and Social Theory. Critical Theory: Diverse Objects, Diverse Subjects, 22, 367-392. https://doi.org/Doi 10.1016/S02781204(03)80017-8

Fisher, C. A., Jabara, J., Poudrier, L., Williams, T., \& Wallen, G. R. (2016). Shared governance: The way to staff satisfaction and retention. Nursing Management, 47(11), 14-16. https://doi.org/10.1097/01.NUMA.0000502808.67918.e8

Gagnon, L., Bakker, D., Montgomery, P., \& Palkovits, J. A. (2010). Nurse autonomy in cancer care. Cancer Nursing, 33(3). https://doi.org/10.1097/NCC.0b013e3181c98985

Gammelgaard, J., McDonald, F., Tüselmann, H., Dörrenbächer, C., \& Stephan, A. (2011). Effective autonomy, organisational relationships and skilled jobs in subsidiaries. Management Research Review, 34(4), 366-385. https://doi.org/10.1108/01409171111117834

Gordon, P. A. (2017). Exploring generational cohort work satisfaction in hospital nurses. Leadership in Health Services, 30(3), 233-248. https://doi.org/10.1108/LHS-02-2016-0008

Houlfort, N., Koestner, R., Joussemet, M., Nantel-Vivier, A., \& Lekes, N. (2002). The impact of performance-contingent rewards on perceived autonomy and competence. Motivation and 
INTERNATIONAL JOURNAL OF ACADEMIC RESEARCH IN BUSINESS AND SOCIAL SCIENCES

Vol. 8, No. 12, Dec, 2018, E-ISSN: 2222-6990 @ 2018 HRMARS

Emotion, 26(4), 279-295. https://doi.org/10.1023/A:1022819120237

Jingnan, S. (2011). Autonomy in EFL Education. Canadian Social Science, 7(5), 27-32. https://doi.org/10.3968/J.css.1923669720110705.381

Kramer, M., \& Schmalenberg, C. E. (2003). Magnet hospital staff nurses describe clinical autonomy. Nursing Outlook, 51(1), 13-19. https://doi.org/10.1067/mno.2003.4

MacDonald, C. (2002). Nurse autonomy as relational. Nursing Ethics, 9(2), 194-201. https://doi.org/10.1191/0969733002ne498oa

Maharmeh, M. (2017). Understanding critical care nurses' autonomy in KSA. Leadership in Health Services, 30, 432-442.

Maharmeh, M., Alasad, J., Salami, I., Saleh, Z., \& Darawad, M. (2016). Clinical Decision-Making among Critical Care Nurses: A Qualitative Study. Health, 8(15), 1807-1819. https://doi.org/10.4236/health.2016.815173

Maylone, M. M., Ranieri, L. A., Griffin, M. T. Q., Mcnulty, R., \& Fitzpatrick, J. J. (2011). Collaboration and autonomy: Perceptions among nurse practitioners. Journal of the American Academy of Nurse Practitioners, 23(1), 51-57. https://doi.org/10.1111/j.1745-7599.2010.00576.x

Mccrae, N. (2012). Whither Nursing Models? The value of nursing theory in the context of evidencebased practice and multidisciplinary health care. Journal of Advanced Nursing, 68(1), 222-229. https://doi.org/10.1111/j.1365-2648.2011.05821.x

Mrayyan, M. T. (2004). Nurses' autonomy: Influence of nurse managers' actions. Journal of Advanced Nursing , 45(3), 326-336. https://doi.org/10.1046/j.1365-2648.2003.02893.x

Parahoo, K. (2000). Barriers to, and facilitators of, research utilization among nurses in Northern Ireland. Journal of Advanced Nursing, 31(1), 89-98. https://doi.org/10.1046/j.13652648.2000.01256.x

Prichard, C., \& Moore, J. E. (2016). Variables influencing teacher autonomy, administrative coordination, and collaboration. Journal of Educational Administration, 54(1), 58-74. https://doi.org/10.1108/JEA-09-2014-0113

Rafferty, A. M., Ball, J., \& Aiken, L. H. (2001). Are teamwork and professional autonomy compatible, and do they result in improved hospital care? Quality and Safety in Health Care, 10(Supplement 2), ii32-ii37. https://doi.org/10.1136/qhc.0100032..

Shaker, C. S., \& Werner Woida, A. M. (2007). An Evidence-Based Approach to Nipple Feeding in a Level III NICU: Nurse Autonomy, Developmental Care, and Teamwork. Neonatal Network: The Journal of Neonatal Nursing, 26(2), 77-83. https://doi.org/10.1891/0730-0832.26.2.77

Sigler, T. H., \& Pearson, C. M. (2000). Creating an empowering culture: examining the relationship between organizational culture and perceptions of empowerment. Journal of Quality Management, 5(1), 27-52. https://doi.org/10.1016/S1084-8568(00)00011-0

Swamy, D. R., \& Rashmi, S. (2015). Quality of Work Life: Scale Development and Validation. International Journal of Caring Sciences, 8(2), 281-300. https://doi.org/10.5958/23942770.2016.00010.7

Turner, C., Keyzer, D., \& Rudge, T. (2007). Spheres of influence or autonomy? A discourse analysis of the introduction of Nurse Practitioners in rural and remote Australia. Journal of Advanced Nursing, 59(1), 38-46. https://doi.org/10.1111/j.1365-2648.2007.04275.x

Varjus, S.-L., Leino-Kilpi, H., \& Suominen, T. (2011). Professional autonomy of nurses in hospital 
INTERNATIONAL JOURNAL OF ACADEMIC RESEARCH IN BUSINESS AND SOCIAL SCIENCES

Vol. 8, No. 12, Dec, 2018, E-ISSN: 2222-6990 @ 2018 HRMARS

settings--a review of the literature. Scandinavian Journal of Caring Sciences, 25(1), 201-7. https://doi.org/10.1111/j.1471-6712.2010.00819.x

Westendorf, J. J. (2007). Magnet recognition program. Plastic Surgical Nursing.

https://doi.org/10.1097/01.PSN.0000278241.00533.ea 